\title{
Transarterial ONYX Embolization of Intracranial Dural Arteriovenous Fistulas in Adults
}

\author{
Jihui LIU, Xinguo LI, Shengxue SUN, Yunjie WANG, Peizhuo ZANG \\ The First Affiliated Hospital of China Medical University, Department of Neurosurgery, Shenyang, China
}

\section{ABSTRACT}

AIM: To present our experience on transarterial treatment of dural arteriovenous fistulas (DAVFs) with ONYX in adult patients.

MATERIAL and METHODS: Between March 2008 and November 2012, 27 adult patients with DAVFs treated by transarterial ONYX embolization were included. Clinical data, including hospital records, operative reports, and angiograms, were reviewed and analyzed.

RESULTS: Complete obliteration of the fistula was achieved in 16/27 (59.3\%) patients after 32 intra-arterial embolizations. One complication (3.7\%) was transient hemiparesis. Follow-up imaging, which was available for 16 fistulas with angiographic cures, showed no evidence of recurrence. At mean 14.5 months follow-up, 26 patients (96.3\%) had GOS score of 5 and 1 patient (3.7\%) had GOS score of 3.

CONCLUSION: Transarterial ONYX embolization has become the main treatment for adult intracranial DAVFs and is associated with high safety and efficacy.

KEYWORDS: Dural arteriovenous fistula, Embolization, ONYX, Radiosurgery

ABBREVIATIONS: AVF: Arteriovenous fistula, CT: Computed tomography, CVR: Cortical venous reflux, DAVF: Dural arteriovenous fistula, DCF: Dural cavernous fistula, ECA: External carotid artery, ICA: Internal carotid artery, IPS: Inferior petrosal sinus, MMA: Middle meningeal artery, VA: Vertebral artery, DAVF: Dural arteriovenous fistula, GOS: Glasgow Outcome Scale.

\section{INTRODUCTION}

In adults, it has been shown that dural arteriovenous fistulas (DAVFs) are an acquired disease. The term dural arteriovenous fistula (DAVF) should therefore be used in adults, rather than in children (34).

The arterial supply of the DAVFs is from the dural arteries and the dural branches of cerebral arteries. This is directly shunted into a venous sinus and/or arterialized leptomeningeal veins. The nidus of the DAVF is usually located within the dura mater $(3,19)$. The venous drainage of DVAF is the most important predictor of the clinical behavior. DAVFs with cortical venous reflux (CVR) exhibit a much higher incidence of hemorrhage or venous infarction (29). The annual mortality rate for DAVFs with CVR may be as high as $10.4 \%$, whereas the annual risk for hemorrhage or non-hemorrhagic neurological deficits during follow-up period are $8.1 \%$ and $6.9 \%$, respectively, resulting in an annual event rate of $15 \%(29,42)$.

In addition, re-bleeding rates are as high as $35 \%$ during the first 2 weeks after the first hemorrhage (10). Therefore, DVAFs need careful evaluation for the best therapeutic option (29).

The current endovascular treatment of DAVFs is sometimes a complex strategy, including not only transarterial injection of any liquid embolic agent but also transvenous approaches and also surgical elements (16). 
With the advent of ONYX (Covidien, Irvine, CA), most intracranial DAVFs can be successfully managed with transarterial ONYX embolization via their supply from the external carotid artery (ECA) branches, which can be safely embolized (29).

In this study, we report our experience with a series of 27 adult patients who underwent intra-arterial embolization for intracranial DAVFs.

\section{- MATERIAL and METHODS}

Between March 2008 and November 2012, 27 (20 males, 7 females) consecutive adult patients with DAVFs treated using transarterial ONYX embolization (Tables I, II). The mean age was 46.3 years (range, $29-70$ years).

Clinical presentations included hemorrhage in 11 patients $(40.7 \%)$, chemosis in 4 patients $(14.8 \%)$, bruit in 9 patients $(33.3 \%)$, headaches in 5 patients $(18.5 \%)$, blurred vision in 1

Table I: Demographic Characteristics of the 27 Patients

\begin{tabular}{|c|c|c|c|c|c|c|c|}
\hline $\begin{array}{l}\text { Patient } \\
\text { No. }\end{array}$ & $\begin{array}{c}\text { Age } \\
\text { (years) }\end{array}$ & Sex & Presentation & Location & Suppliers & $\begin{array}{c}\text { Borden } \\
\text { Type }\end{array}$ & Approach \\
\hline 1 & 44 & M & Bruits & BL, TS Torcula & R, ECANA, L, OA & II & $\mathrm{R}, \mathrm{MMA} ; \mathrm{L}, \mathrm{OA}$ \\
\hline 2 & 40 & $\mathrm{~F}$ & $\begin{array}{l}\text { Chemosis, bruits, blurred } \\
\text { vision }\end{array}$ & $\mathrm{R}, \mathrm{CS}$ & R, ICA/ECA & II & $\mathrm{R}, \mathrm{MMA}$ \\
\hline 3 & 42 & $\mathrm{~F}$ & Headaches & $\mathrm{R}, \mathrm{TS}$ & R, VA; BL, ECA & II & $\mathrm{R}, \mathrm{MMA}$ \\
\hline 4 & 70 & M & Headaches, bruits, chemosis & L, TS & L, ICA/MMA/VA & II & L, MMA \\
\hline 5 & 50 & $\mathrm{~F}$ & Bruits & L, TS & L, OA/MHT/MMA & II & L, MMA; L, OA \\
\hline 6 & 36 & $\mathrm{~F}$ & Headaches, blurred vison & $\mathrm{R}, \mathrm{TS}$ & $\mathrm{BL}, \mathrm{ECA}$ & II & $\mathrm{BL}, \mathrm{MMA} ; \mathrm{R}, \mathrm{OA}$ \\
\hline 7 & 31 & M & Chemosis, bruits & $\mathrm{R}, \mathrm{TS}$ & R, ICA/ECA & II & $\mathrm{R}, \mathrm{MMA}$ \\
\hline 8 & 46 & M & Chemosis & L, CS & L, ICA/ECA & II & L, MMA \\
\hline 9 & 44 & M & $\mathrm{ICH}$ & $\mathrm{R}$, Fronto-parietal & $\mathrm{R}, \mathrm{MMA}$ & III & $\mathrm{R}, \mathrm{MMA}$ \\
\hline 10 & 40 & M & Chemosis & $\mathrm{R}, \mathrm{TS}$ & $\mathrm{BL}$, ECA & III & $\mathrm{R}, \mathrm{MMA}$ \\
\hline 11 & 29 & $M$ & $\mathrm{ICH}$ & $\mathrm{R}, \mathrm{TS}$ & R, ECA/VA; L, OA & III & $\mathrm{R}, \mathrm{MMA}$ \\
\hline 12 & 61 & $\mathrm{M}$ & Trigeminal neuralgia & Meckel Cave & $\mathrm{R}, \mathrm{ECA} / \mathrm{ICA}$ & III & $\mathrm{R}, \mathrm{MMA}$ \\
\hline 13 & 38 & M & $\mathrm{ICH}$ & Ethmoidal & BL, ICA; L, ECA & III & R, Opha \\
\hline 14 & 63 & M & Headaches & $\mathrm{R}$, tentorial & L, MMA; R, ECA/ICA & III & L, MMA \\
\hline 15 & 59 & M & $\mathrm{ICH}$ & $\mathrm{R}$, tentorial & $\mathrm{BL}, \mathrm{ECA} / \mathrm{ICA}$ & III & $\mathrm{BL}, \mathrm{MMA}$ \\
\hline 16 & 56 & M & $\mathrm{ICH}$ & $\mathrm{R}$, tentorial & R, ICA/ECA/AICA & III & $\mathrm{R}, \mathrm{MMA}$ \\
\hline 17 & 47 & M & $\mathrm{ICH}$ & $\mathrm{R}$, tentorial & R, ICA/ECA & III & $\mathrm{R}, \mathrm{MMA}$ \\
\hline 18 & 43 & $\mathrm{~F}$ & $\mathrm{ICH}$ & $\mathrm{R}$, tentorial & $\mathrm{R}, \mathrm{ECA} / \mathrm{ICA}$ & III & $\mathrm{R}, \mathrm{MMA}$ \\
\hline 19 & 35 & M & $\mathrm{ICH}$ & $\mathrm{R}$, tentorial & R, SCA/MMA/MHT & III & $\mathrm{R}, \mathrm{MMA}$ \\
\hline 20 & 35 & M & Hypoesthesia & $\mathrm{R}$, tentorial & $\mathrm{R}, \mathrm{MHT} / \mathrm{SCA}$ & III & $\mathrm{R}, \mathrm{SCA}$ \\
\hline 21 & 51 & $\mathrm{~F}$ & $\mathrm{ICH}$ & Craniocervical junction & L, VA & III & L, PMA \\
\hline 22 & 52 & M & Bruits & Middle cranial fossa & L, ECA & III & L, MMA \\
\hline 23 & 31 & $\mathrm{~F}$ & Bruits & $\begin{array}{c}\mathrm{L}, \mathrm{TS} \\
\text { SSS } \\
\mathrm{R} \text {, fronto-parietal }\end{array}$ & $\begin{array}{l}\text { BL, ECA } \\
\text { L, MCA }\end{array}$ & $\begin{array}{l}\text { II } \\
\text { III } \\
\text { III }\end{array}$ & $\mathrm{BL}, \mathrm{MMA}$ \\
\hline 24 & 38 & M & Bruits & L, TS & L, ECA/ICA; R, OA & III & $\mathrm{R}, \mathrm{OA}$ \\
\hline 25 & 69 & M & Bruits & L, fronto-parietal & $\mathrm{BL}, \mathrm{MMA}$ & III & L, MMA \\
\hline 26 & 43 & M & $\mathrm{ICH}$, headaches, bruits & $\mathrm{L}$, tentorial & L, ECA/ICA & III & L, MMA \\
\hline 27 & 56 & M & $\mathrm{ICH}$ & L, clival & L, MHT & III & L, MHT \\
\hline
\end{tabular}

M: Male; F: Female, ICH: Intracranial hemorrhage, CN: Cranial nerve, TS: Transverse sigmoid, ECA: External carotid artery, ICA: Internal carotid artery, OA: Occipital artery, VA: Vertebral artery, CS: Cavernous sinus, Opha: Ophthalmic artery, SSS: Superior sagittal sinus, MMA: Middle meningeal artery, SCA: Superior cerebellar artery, MHT: Meningohypophyseal trunk, PMA: Posterior meningeal artery. 
patient (3.7\%), hypoesthesia in 1 patient (3.7\%), and trigeminal neuralgia in 1 patient (3.7\%). Multiple dural fistulas occurred in 2 patients $(7.4 \%)$.

The locations of the lesions were transverse-sigmoid sinus in 10 patients $(37.0 \%)$, cavernous sinus in 1 patients $(3.7 \%)$, tentorium in 8 patients $(29.6 \%)$, ethmoidal in 1 patients $(3.7 \%)$, frontoparietal in 3 patients (11.1\%), saggital sinus in 1 patients $(3.7 \%)$, Meckel cave in 1 patient $(3.7 \%)$, middle fossa dura in 1 patients $(3.7 \%)$, clivus in 1 patient $(3.7 \%)$, craniocervical junction in 1 patient (3.7\%) and torcula in 1 patient (3.7\%).

According to Borden classification (4), 8 fistulas (29.6\%) were type II, and 19 (70.4\%) were type III.

All endovascular approaches were performed under general anesthesia. Diagnostic angiography was performed including six vessels. Cervical branches of the subclavian artery were

Table II: Treatment and Follow-Up of the 27 Patients

\begin{tabular}{|c|c|c|c|c|c|c|c|}
\hline $\begin{array}{l}\text { Patient } \\
\text { No. }\end{array}$ & $\begin{array}{c}\text { Injection } \\
\text { time (minutes) }\end{array}$ & Material & $\begin{array}{l}\text { Adjunct } \\
\text { treatment }\end{array}$ & $\begin{array}{l}\text { Angiographic } \\
\text { result }\end{array}$ & Complications & $\begin{array}{l}\text { Follow-up } \\
\text { (months) }\end{array}$ & $\begin{array}{c}\text { Clinical } \\
\text { outcome (GOS) } \\
\text { score }\end{array}$ \\
\hline 1 & 110 & ONYX & NO & Incomplete & no & 24 & 5 \\
\hline 2 & 20 & ONYX & Radiosurgery & Incomplete & no & 10 & 5 \\
\hline 3 & 40 & ONYX & NO & Incomplete & no & 25 & 5 \\
\hline 4 & 55 & ONYX & NO & Complete & no & 7 & 5 \\
\hline 5 & 75 & ONYX & NO & Incomplete & no & 15 & 5 \\
\hline 6 & 80 & ONYX & NO & Incomplete & no & 9 & 5 \\
\hline 7 & 30 & ONYX & NO & Incomplete & no & 13 & 5 \\
\hline 8 & 15 & ONYX & NO & Incomplete & no & 16 & 5 \\
\hline 9 & 40 & ONYX & NO & Complete & no & 29 & 5 \\
\hline 10 & 20 & ONYX & NO & Complete & no & 4 & 5 \\
\hline 11 & 15 & ONYX & NO & Complete & no & 5 & 5 \\
\hline 12 & 33 & ONYX & Radiosurgery & Incomplete & no & 1 & 5 \\
\hline 13 & 30 & ONYX & NO & Incomplete & no & 1 & 5 \\
\hline 14 & 50 & ONYX & NO & Complete & no & 25 & 5 \\
\hline 15 & 45 & ONYX & NO & Complete & no & 12 & 3 \\
\hline 16 & 20 & ONYX & NO & Complete & no & 16 & 5 \\
\hline 17 & 25 & ONYX & NO & Complete & no & 3 & 5 \\
\hline 18 & 15 & ONYX & NO & Complete & no & 20 & 5 \\
\hline 19 & 15 & ONYX & NO & Complete & $\begin{array}{c}\text { R, ICA stenosis, } \\
\text { hemiparesis }\end{array}$ & 13 & 5 \\
\hline 20 & 15 & ONYX & NO & Complete & no & 24 & 5 \\
\hline 21 & 25 & ONYX & NO & Complete & no & 12 & 5 \\
\hline 22 & 10 & ONYX & NO & Complete & no & 25 & 5 \\
\hline 23 & 44 & ONYX & NO & Incomplete & no & 20 & 5 \\
\hline 24 & 30 & ONYX & NO & Complete & no & 21 & 5 \\
\hline 25 & 25 & ONYX & NO & Complete & no & 16 & 5 \\
\hline 26 & 15 & ONYX & Radiosurgery & Incomplete & no & 24 & 5 \\
\hline 27 & 4 & ONYX & Balloon assistance & Complete & no & 1 & 5 \\
\hline
\end{tabular}

GOS: Glasgow outcome scale. 
included in selected cases. The decision of embolization, the route, and the embolizing material were chosen based on the angiographic findings (29). After transfemoral access and sheath placement, the patient was heparinized, with 3000 units intravenously and 1000 units per hour of intravenous heparin, to maintain an activated coagulation time of between 250 and 300 seconds (29). Standard coaxial techniques were used for embolization. Guide catheters were navigated into the appropriate parent vessel (external carotid artery, internal carotid artery, or vertebral artery) (38). A DMSO compatible microcatheter (Marathon or Echelon; Covidien) with a microwire (Mirage or Silverspeed; Covidien) was then advanced into the selective branches as close to the nidus as possible and allowing for an adequate distance for reflux of the embolic agent, and superselective angiography was performed on the target branch or branches for embolization $(29,38)$. When there were multiple feeders, the feeder with maximum reflux distance from the skull base was chosen to decrease the chances of cranial nerve palsies (29). Embolization of the DAVF was then performed with ONYX-18 in the manner previously described (26-28). If the meningohypophyseal trunk was catheterized, ONYX embolization was performed with balloon assistance. The end point of the embolization was the angiographic obliteration of the fistula, with some filling of the draining veins (Figure 1A, B).

Clinical follow-up (mean 13.2 months, range 1-29 months) data were supplemented by telephonic interviews and graded according to the Glasgow Outcome Scale (GOS) (18). An excellent outcome was defined as the resumption of normal life despite minor deficits (GOS Score 5). A good outcome was a moderate disability, but the patient was independent (GOS Score 4). A fair outcome was a severe disability, and the patient was dependent on the care of others (GOS Score 3). A poor outcome was a persistent vegetative state (GOS Score 2) or death (GOS Score 1). Most patients had follow-up angiograms approximately $6-11$ months after the embolization procedure.
The angiographic results of treatment were classified as incomplete or complete, based on the evidence of remnant fistula on the post-treatment angiogram.

\section{RESULTS}

Thirty-two intra-arterial ONYX embolization procedures were performed to treat dural fistulas in 27 patients (Table I). There were 32 transarterial approaches, 1 of which was performed with balloon assistance. Thirty-two ONYX injections were performed in 32 vessel branches, including 28 ECA branches, posterior meningeal artery $(n=1)$, ophthalmic artery $(n=1)$, meningohypophyseal artery $(n=1)$, superior cerebellar artery $(n=1)$.

Twenty-three branches of the middle meningeal artery (MMA) were embolized along with 5 branches of the occipital artery. Thirteen lesions were cured with transarterial treatment via the MMA alone (Figure 1). Three fistulas were cured with transarterial treatment via the superior cerebellar artery, meningohypophyseal artery and posterior meningeal artery.

Three patients underwent Gamma Knife radiosurgery, which was performed after incomplete embolization. Only one technical complication was associated with the transarterial ONYX embolization, resulting in a complication rate of $3.1 \%$. A 35-year-old man presented with subarachnoid hemorrhage caused by a tentorial DAVF with supply from the right meningohypophyseal trunk, the right superior cerebellar artery and the right middle meningeal artery. The patient underwent transarterial ONYX embolization via the MMA. At the final stage, a small amount of ONYX appeared to reflux into the right internal carotid artery (ICA) via the meningophypophyseal trunk. Therefore, ONYX embolization was aborted, and the catheter was removed. Then, immediate angiography revealed complete occlusion of the fistula. The patient experienced left hemiparesis just after the procedure and discharged home on postoperative day 5 . The hemiparesis had almost resolved completely at the fifteenth day after the embolization.

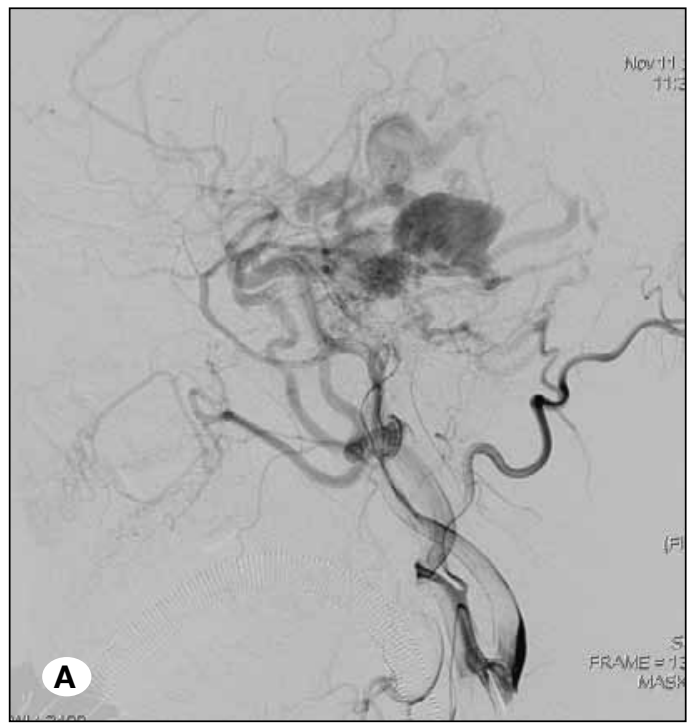

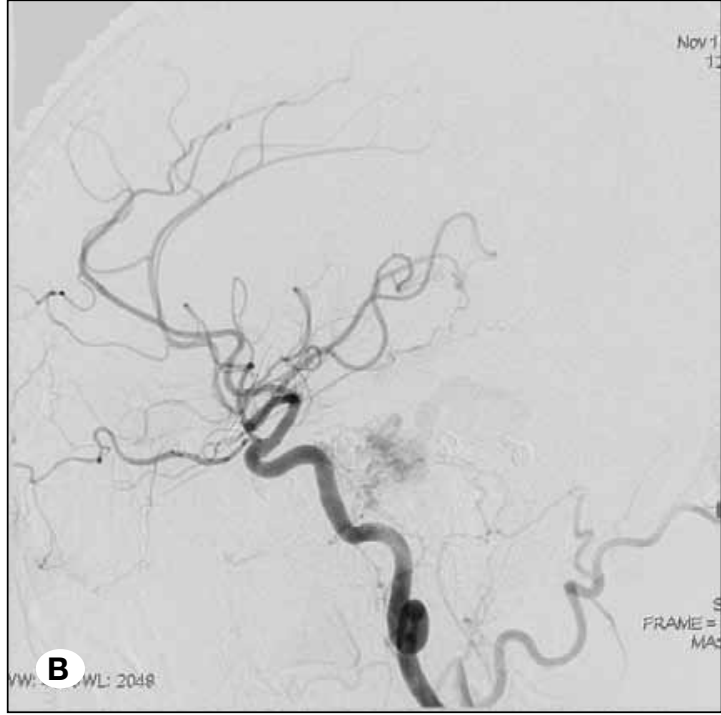

Figure 1: A) left carotid artery angiogram (lateral view) demonstrating a left tentorial DAVF with supply from the left MMA and occipital artery and venous drainage into a cortical vein with a dilated venous varix that drains into the lateral mesencephalic veins. B) post-embolization left ICA angiogram (lateral view) showing residual fistula supplied by the meningeal hypophyseal trunk. 
Of the 27 patients who had endovascular treatment, 16 (59.3 $\%)$ had complete obliteration of the fistula after embolization. Of the 11 fistulas, in which endovascular treatment was incomplete, 3 underwent radiosurgery. In the remaining 8 fistulas, the fistula was treated nearly complete obliteration or the post-embolization fistula was Borden type I, and the residual fistula remained stable on the follow-up angiogram, and no further treatment was performed.

Of the 3 fistulas that underwent Gamma Knife radiosurgery, complete fistula obliteration was confirmed by 2-year followup angiogram in 2 and 1 will have follow-up angiography 2 years post-treatment.

Twenty-six of 27 patients (96.3\%) had a favorable outcome (GOS score 5) during the follow-up period. One patient with GOS score 3, the cause for the poor outcome was the initial insult of the hemorrhage. In our series, there was no procedure-related mortality.

\section{DISCUSSION}

The pathogenesis of DAVFs is still unclear, with a congenital and an acquired etiology having been proposed (19, 29). Lasjaunias et al. (19) proposed that a primary structural weakness of the dura coincides with a trigger factor and results in the formation of a DAVF (29). The common predisposing factor appears to be venous sinus thrombosis, with the body compensating for this by attempts at recanalization $(12,13,17,29)$. In our series, sinus occlusion was observed in 8 patients. There were 2 patients with multifocal complex DAVFs in adults; and in 26 patients, no specific cause could be identified. We have a male predominance (76.9\%) in our patients and this may suggest that it tends to have a more aggressive course in men $(16,34,41)$.

The incidence of DAVF by location, as reported in the literature, is as follows: transverse sigmoid sinus, $50 \%$; cavernous sinus, $16 \%$; tentorium, $12 \%$; superior sagittal sinus, $8 \%$, and anterior fossa, 2\% (2, 4, 8, 25, 29).

A patient's first hemorrhage from a DAVF is associated with $20 \%$ to $30 \%$ mortality, emphasizing the importance of early recognition and treatment of patients at highest risk $(5,29)$. The natural history of DAVFs has been poorly documented until recently and has been based on retrospective reviews $(2,8,29)$. Van Dijk et al. (42) had a 4.3 years follow-up on their 14 non-treated patients and 6 partially-treated patients. They found that persistence of the CVR in cranial DAVFs yielded an annual mortality rate of $10.4 \%$.

Recent studies demonstrate evidence that the risk of bleeding for a DAVF with CVR is less when the patient does not present with a hemorrhage or a nonhemorrhagic neurologic deficit $(29,37,39)$. Strom et al. (39) report that asymptomatic versus symptomatic DAVFs (in patients presenting with hemorrhage or neurologic deficit) have annual hemorrhage rates of $1.4 \%$ versus $19 \%$, respectively. Although small in size, these studies make the important point that the natural history may depend on the type of presentation $(29,39)$. Nevertheless, lower annual hemorrhage rates of asymptomatic type II and III DAVFs (up to $1.5 \%$ per year) $(29,37)$ still pose significant long-term risk to patients, thereby justifying treatment in appropriately selected patients (29). Our patients belonged to the high-risk category (Borden types II or III) and required active intervention to prevent risk of hemorrhage.

At our institution, we perform aggressive treatment for symptomatic type II/III DAVFs. We also recommend treatment in asymptomatic type II/III DAVFs if the patient is a good candidate for embolization on the basis of their age, lifetime hemorrhage risk profile, and willingness or unwillingness to accept the natural history.

Currently, several series have established a high degree of safety and efficacy of ONYX used intra-arterially and intra-venously in the treatment of intracranial DAVFs $(1,6,9,29,31,32,40)$. The complete obliteration rate in arterial ONYX embolization was $61.3 \%-91.6 \%(22,31-33,40)$ and that in venous ONYX embolization was $100 \%(21,23)$. The efficiency of access through the MMA, even when the diameter was very small, than through other more dilated feeders (eg, occipital and posterior auricular arteries) due to the superior flow control and reliability of target vessel embolization has been described well in literatures $(15,20,29,38)$. ONYX offers the possibility of venous sinus packing/occlusion from an arterial side approach, which may be quite helpful in cases with previous occlusion of the draining venous structures $(14,29)$.

Post-embolization complication rates of approximately $2 \%$ to $10 \%$ have been reported in most series $(11,22,24,29,30)$. Complications associated with arterial embolization include cranial nerve deficits, draining vein occlusion or venous ONYX migration, brain infarction, reflexive bradycardia, brain infraction and microcatheter gluing $(22,24)$. On our experience, complications associated with venous embolization were reflexive bradycardia and transient cranial nerve deficits. Our success rate of $63.9 \%$ seems comparable with previously reported results of $50 \%$ to $90 \%(6,7,9,31)$ and our complication rate was as low as $2.8 \%$.

The petrous branch of the middle meningeal trunk supplies the cranial nerves at the skull base (29). We avoid this branch and select another distal tentorial branch to embolize the fistula, even if that is not a direct feeder. The arterial or venous balloon assistance technique provides an adjunctive method in the transarterial and transvenous ONYX embolization of complex DAVFs (36). The balloon can be inflated in the ICA or vertebral arteries at the site of the meningeal feeding arteries, which have anastomotic connections with the target vessel being embolized (36). This technique prevented the untoward passage of ONYX into the ICA via the meningophypophyseal branch and vertebral artery via the posterior meningeal artery. It can thus prevent the embolic material from occluding the intracranial artery and/or causing distal embolism via those anastomotic channels (36). This technique is especially useful in DAVFs because of the rapid tapering, small-diameter feeding arteries resulting in early reflux during ONYX injection (36).

Shi et al. have used the venous balloon assistance technique to prevent ONYX from inadvertently occluding the lumen of a functioning venous sinus and migrating into adjacent key 
cortical or deep veins when the balloon occludes the recipient venous structure (36).

Radiosurgery is inefficient for DAVFs and it may be tried where embolization has failed and surgery appears to carry a high risk $(25,29,44)$. Wu et al. reported a $75 \%$ angiographic obliteration rate at 24 months (43). In our series Gamma Knife radiosurgery was used in 3 patients. Complete obliteration has been achieved in 2 with 1 awaited for 2-year follow-up angiogram.

Surgery is indicated for high-risk DAVFs with leptomeningeal retrograde venous drainage when embolization is technically difficult or has resulted in incomplete occlusion $(29,35)$.

\section{- CONCLUSION}

Transarterial ONYX embolization has become the main treatment for adult intracranial DAVFs and is associated with high safety and efficacy.

\section{REFERENCES}

1. Arat $A$, Inci S: Treatment of a superior sagittal sinus dural arteriovenous fistula with Onyx: Technical case report. Neurosurgery 59:ONSE169-170, 2006

2. Awad IA, Little JR, Akarawi WP, Ahl J: Intracranial dural arteriovenous malformations: Factors predisposing to an aggressive neurological course. J Neurosurg 72:839-850, 1990

3. Barnwell SL, Halbach VV, Dowd CF, Higashida RT, Hieshima GB, Wilson CB: A variant of arteriovenous fistulas within the wall of dural sinuses. Results of combined surgical and endovascular therapy. J Neurosurg 74: 199-204, 1991

4. Borden JA, Wu JK, Shucart WA: A proposed classification for spinal and cranial dural arteriovenous fistulous malformations and implications for treatment. J Neurosurg 82:166-179, 1995

5. Brown RD Jr, Wiebers DO, Nichols DA: Intracranial dural arteriovenous fistulae: Angiographic predictors of intracranial hemorrhage and clinical outcome in nonsurgical patients. $J$ Neurosurg 81: 531-538, 1994

6. Chew J, Weill A, Guilbert F, Raymond J, Audet ME, Roy D: Arterial Onyx embolisation of intracranial DAVFs with cortical venous drainage. Can J Neurol Sci 36: 168-175, 2009

7. Chong WKW, Holt M: Endovascular therapy for intracranial dural arteriovenous fistulas. Neuroradiol J 19: 537-549, 2006

8. Cognard C, Gobin YP, Pierot L, Bailly AL, Houdart E, Casasco A, Chiras J, Merland JJ: Cerebral dural arteriovenous fistulas: Clinical and angiographic correlation with a revised classification of venous drainage. Radiology 194:671-680, 1995

9. Cognard C, Januel AC, Silva NA Jr, Tall P: Endovascular treatment of intracranial dural arteriovenous fistulas with cortical venous drainage: New management using Onyx. AJNR Am J Neuroradiol 29: 235-241, 2008

10. Duffau H, Lopes M, Janosevic V, Sichez JP, Faillot T, Capelle L, Isma M, Bitar A, Arthuis F, Fohanno D: Early rebleeding from intracranial dural arteriovenous fistulas: Report of 20 cases and review of the literature. J Neurosurg 90:78-84, 1999
11. Higashida RT, Halbach VV, Dowd CF, Hieshima GB: Endovascular surgical approach to intracranial vascular diseases. J Endovasc Surg 3:146-157, 1996

12. Jiang C, Lv X, Li Y, Liu A, Lv M, Jiang P, Wu Z: Transvenous embolization of cavernous sinus dural arteriovenous fistula with Onyx-18 and plentinum coils: Technical Note. Neuroradiol J 20: 47-52, 2007

13. Jiang C, Lv X, Li Y, Liu A, Wu Z: Transvenous embolization with Onyx for dural arteriovenous fistula of cavernous sinus: $A$ report of two case reports. Neuroradiol J 20:718-725, 2007

14. Jiang C, Lv X, Li Y, Wu Z: Transarterial Onyx packing of the transverse-sigmoid sinus for dural arteriovenous fistulas. Eur J Radiol 80:767-770, 2011

15. Jiang C, Lv X, Li Y, Zhang J, Wu Z: Endovascular treatment of high-risk tentorial dural arteriovenous fistulas: Clinical outcomes. Neuroradiology 51:103-111, 2009

16. Kuwayama N, Kubo M, Tsumura K, Yamamoto H, Endo S: Hemodynamic status and treatment of aggressive dural arteriovenous fistulas. Acta Neurochir Suppl 94:123-126, 2005

17. Lasjaunias $P$, Berenstein A, Raybaud C: Surgical Neuroangiography. Berlin: Springer-Verlag, 1987

18. Lasjaunias $P$, Chiu $M$, ter Brugge $K$, Tolia $A$, Hurth $M$, Bernstein M: Neurological manifestations of intracranial dural arteriovenous malformations. J Neurosurg 64: 724-730, 1986

19. Lasjaunias P, Magufis A, Goulao R, Suthipongchai S, Rodesch $\mathrm{R}$, Alvarez $\mathrm{H}$ : Anatomoclinical aspects of dural arteriovenous shunts in children. Intervent Neuroradiol 2:179-191, 1996

20. Lucas Cde P, Mounayer C, Spelle L, Piotin M, Rezende MT, Moret $\mathrm{J}$ : Endoarterial management of dural arteriovenous malformations with isolated sinus using Onyx-18: Technical case report. Neurosurgery 61(5 Suppl 2):E293-294, 2007

21. Lv X, Jiang C, Li Y, Wu Z: Percutaneous transvenous packing of cavernous sinus with Onyx for cavernous dural arteriovenous fistula. Eur J Radiol 71:356-362, 2009

22. Lv X, Jiang C, Li Y, Wu Z: Results and complications of transarterial embolization of intracranial dural arteriovenous fistulas using Onyx-18. J Neurosurg 109:1083-1090, 2008

23. Lv X, Jiang C, Li Y, Yang X, Wu Z: Recovery of opthalmoplegia associated with cavernous sinus dural arteriovenous fistulas after transvenous cavernous sinus packing. Eur $\mathrm{J}$ Radiol 75:139-142, 2010

24. Lv X, Jiang C, Zhang J, Li Y, Wu Z: Complications related to percutaneous transarterial embolization of intracranial dural arteriovenous fistulas in 40 patients. AJNR Am J Neuroradiol $30: 462-468,2009$

25. Lv X, Jiang C, Li Y, Liu L, Liu J, Wu Z: Transverse-sigmoid sinus dural arteriovenous fistulae. World Neurosurg 74: 297 305, 2010

26. Lv X, Jiang C, Li Y, Yang X, Wu Z: Transarterial embolization of tentorial dural arteriovenous fistulas with Onyx-18. Neuroradiol J 21:406-414, 2008

27. Lv X, Li Y, Liu A, Jiang C, Wu Z: Transarterial embolization of dural arteriovenous fistulas of the anterior cranial fossa Onyx18: Case report. Neuroradiol J 20:53-59, 2007 
28. Natarajan SK, Ghodke B, Britz GW, Born DE, Sekhar LN: Multimodality treatment of brain arteriovenous malformations with microsurgery after embolization with onyx: Single-center experience and technical nuances. Neurosurgery 62:12131226, 2008

29. Natarajan SK, Ghodke B, Kim LJ, Hallam DK, Britz GW, Sekhar $\mathrm{LN}$ : Multimodality treatment of intracranial dural arteriovenous fistulas in the Onyx era: A single center experience. World Neurosurg 73(4):365-379, 2010

30. Ng PP, Higashida RT, Cullen S, Malek R, Halbach VV, Dowd CF: Endovascular strategies for carotid cavernous and intracerebral dural arteriovenous fistulas. Neurosurg Focus 15:ECP1, 2003

31. Nogueira RG, Dabus G, Rabinov JD, Eskey CJ, Ogilvy CS, Hirsch JA, Pryor JC: Preliminary experience with onyx embolization for the treatment of intracranial dural arteriovenous fistulas. AJNR Am J Neuroradiol 29:91-97, 2008

32. Panagiotopoulos V, Moller-Hartmann W, Asgari S, Sandalcioglu IE, Forsting M, Wanke IL: Onyx embolization as a first line treatment for intracranial dural arteriovenous fistulas with cortical venous reflux. Rofo 181:129-138, 2009

33. Rezende MT, Piotin M, Mounayer C, Spelle L, Abud DG, Moret J: Dural arteriovenous fistula of the lesser sphenoid wing region treated with Onyx: Technical note. Neuroradiology 48:130-134, 2006

34. Sarma D, ter Brugge K: Management of intracranial dural arteriovenous shunts in adults. Eur J Radiol 46:206-220, 2003

35. Schuette AJ, Cawley CM, Barrow DL: Indocyanine green videoangiography in the management of dural arteriovenous fistulae. Neurosurgery 67:658-662, 2010

36. Shi ZS, Loh Y, Duckwiler GR, Jahan R, Vinuela F: Balloonassisted transarterial embolization of intracranial dural arteriovenous fistulas. J Neurosurg 110:921-928, 2009
37. Soderman M, Pavic L, Edner G, Holmin S, Andersson T: Natural history of dural arteriovenous shunts. Stroke 39:17351739, 2008

38. Stiefel MF, Albuquerque FC, Park MS, Dashti SR: McDougall CG: Endovascular treatment of intracranial dural arteriovenous fistulae using Onyx: A case series. Neurosurgery 65 ONS Suppl 1:ons132-ons140, 2009

39. Strom RG, Botros JA, Refai D, Moran CJ, Cross DT 3rd, Chicoine MR, Grubb RL Jr, Rich KM, Dacey RG Jr, Derdeyn CP, Zipfel GJ: Cranial dural arteriovenous fistulae: Asymptomatic cortical venous drainage portends less aggressive clinical course. Neurosurgery 64:241-248, 2009

40. Toulgoat F, Mounayer C, Tulio Salles Rezende M, Piotin M, Spelle L, Lazzarotti G, Desal H, Moret J: Transarterial embolisation of intracranial dural arteriovenous malformations with ethylene vinyl alcohol copolymer (Onyx18). J Neuroradiol 33:105-114, 2006

41. Toya S, Shiobara R, Izumi J, Shinomiya Y, Shiga H, Kimura C: Spontaneous carotid-cavernous fistula during pregnancy or in the postpartum stage. Report of two cases. J Neurosurg 54:252-256, 1981

42. van Dijk JM, terBrugge KG, Willinsky RA, Wallace MC: Clinical course of cranial dural arteriovenous fistulas with long-term persistent cortical venous reflux. Stroke 33: 1233-1236, 2002

43. Wu HM, Pan DH, Chung WY, Guo WY, Liu KD, Shiau CY, Wang LW, Chen SJ: Gamma Knife surgery for the management of intracranial dural arteriovenous fistulas. J Neurosurg 105 Suppl:43-51, 2006

44. Yang $\mathrm{H}$, Kano $\mathrm{H}$, Kondziolka D, Niranjan A, Flickinger JC, Horowitz MB, Lunsford LD: Stereotactic radiosurgery with or without embolization for intracranial dural arteriovenous fistulas. Neurosurgery 67:1276-1285, 2010 